\title{
VEINTICINCO AÑOS DE PREÁMBULO CONSTITUCIONAL
}

\author{
JAVIERTAJADURA TEJADA \\ Profesor Titular de Derecho Constitucional \\ Universidad del País Vasco
}




\section{SUMARIO}

1. INTRODUCCIÓN. 2. SOCIEDAD DEMOCRÁTICA AVANZADA, MUNDIALIZACIÓN E INTEgración europea. 3. Preámbulo constitucional, sentimiento constitucional y enseñanza de la Constitución. 4. Preámbulo constitucional, reconCILIACIÓN NACIONAL Y MEMORIA HISTÓRICA. 


\title{
VEINTICINCO AÑOS DE PREÁMBULO CONSTITUCIONAL
}

\author{
POR \\ JAVIER TAJADURA TEJADA* \\ Profesor Titular de Derecho Constitucional \\ Universidad del País Vasco
}

\section{INTRODUCCIÓN}

En los veinticinco años de vida constitucional que nos disponemos a celebrar, el Texto de 1978, como es bien sabido, sólo ha sido reformado en una ocasión. Ahora bien, ello no quiere decir que el significado $y$ alcance de muchas disposiciones constitucionales no hayan experimentado cambios de notable envergadura y de extraordinaria importancia. EI Título VIII relativo a la organización territorial del Estado nos ofrece múltiples ejemplos de este fenómeno. Dicho con otras palabras, aunque la Constitución solo ha sido objeto de una única reforma (cambio formal), ha sufrido, sin embargo, decenas de mutaciones (cambios no formales). La legitimidad de muchas de ellas resulta harto problemática. Tal es el caso de la experimentada por el Preámbulo Constitucional. En las páginas que siguen, en primer lugar, voy a intentar exponer, con la brevedad exigida, el alcance de esa mutación. Concluiré mi reflexión sobre el Preámbulo constitucional veinticinco años después, poniendo de manifiesto lo que, en mi modesta

* Es autor de El Preámbulo Constitucional, Editorial Comares, Granada, 1997 (305 páginas). 
opinión, son dos asignaturas pendientes de nuestra democracia: la inclusión de la enseñanza de los valores constitucionales en los planes de estudio, y la recuperación de la memoria histórica de la dictadura de Franco y la II República. En relación con la primera, el Preámbulo es un instrumento sumamente útil para la transmisión del sentimiento constitucional, y sin embargo, hasta la fecha, se ha prescindido por completo de él; en relación con la segunda, hay que tener en cuenta que es función típica de todo Preámbulo Constitucional dar cuenta del inmediato pasado histórico que el nuevo orden constitucional pretende superar. En nuestro caso, ello no fue posible hace veinticinco años y cabe preguntarse si lo sería hoy.

\section{SOCIEDAD DEMOCRÁTICA AVANZADA, MUNDIALIZACIÓN E INTEGRACIÓN EUROPEA}

Como he señalado en múltiples ocasiones, el Preámbulo de la Constitución de 1978 se configura, en cierta medida, como el testamento político del grupo Tierno. Efectivamente, éste se extinguiría poco después de la aprobación de la Constitución ${ }^{1}$. Nada de extraño tiene, por tanto, que las ideas básicas del Texto preambular se enmarquen dentro de unas coordenadas intelectuales y políticas que convergen en una determinada concepción del socialismo como progreso, esto es, en palabras del propio profesor Tierno como "forma de luchar por el mejoramiento de la especien.

El Preámbulo de la Constitución al sintetizar el telos de la misma, realiza una clara y expresa opción por el "progreso" (de la economía, de la cultura, de la democracia, etc.) traducida en términos jurídico-constitucionales como la voluntad de establecer "una sociedad democrática avanzada».

Veinticinco años después debemos realizar un balance sobre la vigencia, significado y alcance actuales, delTexto preambular, en general, y de ese sintagma que sintetiza su completo contenido (sociedad democrática avanzada), en particular. ¿Cuáles eran los niveles de libertad e igualdad, elementos esenciales de toda sociedad democrática,

1 Afortunadamente, el grupo Tierno, en su dimensión intelectual y académica, no sólo sobrevivió al grupo en su faceta estrictamente política, sino también a su fundador, de modo que hoy, veinticinco años después, continúa albergando en su seno a algunos de los más lúcidos y cualificados constitucionalistas de nuestra época. 
hace veinticinco años y cuáles son hoy? En este sentido, y aun con todas las matizaciones que añadiré en las páginas que siguen, creo que hay que afirmar con rotundidad y con contundencia que, salvo que se pretenda falsificar la realidad y la historia, el balance de estos últimos veinticinco años es extraordinariamente positivo.

En ningún otro momento de nuestra secular historia, hemos disfrutado los españoles de los niveles de libertad e igualdad de los que hoy gozamos. Esto resulta muy claro en relación con los derechos clásicos de libertad, en los que prevalece la idea de no injerencia del poder. Pero también respecto a los derechos sociales, en los que prevalece la idea de una prestación pública, a pesar del largo camino que queda aún por recorrer, se han dado pasos de singular importancia. La labor desarrollada en este sentido por los gobiernos de Felipe González durante los años ochenta en lo que se refiere a la universalización de los derechos a la salud, a la educación y a las pensiones, es un hito de indudable trascendencia en nuestra historia. Hasta tal punto esto es así que me atrevo a aventurar que cuando, con más distancia, y por tanto también con más objetividad, se haga balance del periodo histórico que hoy analizamos (1978-2003), la universalización de los mencionados derechos será considerada como el fenómeno histórico de mayor calado y alcance. $Y$ que, del mismo modo, no serán los escándalos económicos ni la corrupción -que, a lo sumo, y a pesar de la lógica relevancia que adquirieron en su momento, quedarán relegados a meras notas a pie de página - los aspectos más negativos del balance, sino las graves carencias existentes en orden a garantizar derechos sociales fundamentales tan básicos como el de la vivienda $u$ otros relacionados con los servicios sociales en el ámbito de la infancia y de la tercera edad.

Por ello, creo oportuno advertir que, la universalización de estos derechos (vivienda y servicios sociales a la infancia y a la tercera edad) debe contemplarse como el próximo paso que habría que dar en esa senda del progreso democrático y social marcada por nuestro Preámbulo. Estoy seguro de que más de uno sonreirá al leer esta afirmación, reputándola como utópica en el sentido de inalcanzable. Ante esas sonrisas sólo cabe recordar algo tan evidente como que en un pasado, no tan lejano, se consideraba igualmente como un ideal de imposible realización la universalización del derecho a la salud y a la educación. En comparación con la dificultad que el logro de estos últimos objetivos implicaba (medios humanos, materiales y financieros), la garantía efectiva del derecho a la vivienda o a los servicios sociales resulta una empresa de más fácil realización. 
Empresa, no obstante, que se ve dificultada, gravemente, por determinadas circunstancias políticas, económicas e ideológicas de lo que hemos dado en denominar la globalización o mundialización, así como por la lógica economicista que informa $y$ preside el proceso de integración continental de la Unión Europea. Creo, por ello, necesario, dedicar las páginas que siguen a exponer cómo la lógica económica que subyace en el proceso de mundialización, en general, y en la Unión Europea, en particular, es la principal amenaza que se cierne sobre la voluntad preambular de alcanzar una "sociedad democrática avanzada", veinticinco años después de que tan ambicioso y noble objetivo fuera formulado por el constituyente de 1978.

Entre las consecuencias de la globalización adversas para el régimen democrático cabe subrayar una que, a medio o largo plazo, podria llegar a provocar la desaparición del Estado Constitucional (Ruipérez): el predominio de los poderes privados (oligárquicos y defensores de intereses igualmente privados) sobre los poderes públicos estatales (democráticos y defensores del interés general). En el contexto de la mundialización económica, es un hecho, fácilmente perceptible, que el poder de los representantes legítimos del pueblo, elegidos por él en el ejercicio del derecho de participación política, resulta cada vez más reducido. Esto es, la vida de los ciudadanos no depende ya tanto de las decisiones políticas que tomen sus representantes, como de las decisiones que adopten otros poderes, privados (las grandes corporaciones económicas transnacionales) y muchas veces ocultos. Estos poderes invisibles, pero no por ello menos reales, son los que gobiernan la economía y, por ende, determinan la calidad y las condiciones de vida de los ciudadanos $y$, a veces, el destino de enteros Estados. A lo anterior hay que añadir el hecho de que incluso dentro del propio Estado proliferan por doquier las Ilamadas Administraciones Independientes, esto es sectores de la Administración que, en nombre de la razón tecnocrática, se dejan en manos de unos gestores que no han de rendir cuentas a los ciudadanos. Nada de extraño tiene que, bajo estas circunstancias, İos márgenes de actuación política se reduzcan y los programas de los partidos tiendan a converger. Convergencia que se produce en mayor medida por asumir las fuerzas de izquierda elementos de los programas conservadores (privatizaciones, bajadas de impuestos). Consecuencia inevitable de lo anterior es el alejamiento de los ciudadanos de la política, al no encontrar interés alguno en verse relegados a la menesterosa condición de espectadores de una realidad que aquéllos a los que correspondería transformarla, la presentan, por el contrario, como inmutable. 
$Y$ es aquí donde reside, en mi opinión, la mayor falacia de muchos de los discursos sobre la globalización y la que, desde los valores y principios que inspiran e informan el Preámbulo constitucional, desde una concepción ilustrada del progreso, es preciso rechazar con toda rotundidad. Dicha falacia consiste en afirmar que la realidad es inmutable puesto que la mundialización económica se produce en virtud de unas hipotéticas leyes históricas o naturales contra las que no podemos luchar. Las tesis de Fukuyama sobre el fin de la historia, a pesar de su inconsistencia, simplicidad, y falsedad, han contaminado demasiados discursos.

En estas circunstancias hay que reconocer que son muchos y muy encomiables los intentos intelectuales de humanizar la globalización, esto es de dar un sentido político y moral al proceso de mundialización económica. Entre ellos destacan muy particularmente los de aquéllos que partiendo de la consideración de la globalización económica como un hecho irreversible apelan a la configuración de formas de organización políticas universales.

Ahora bien, todas esas construcciones intelectuales en las que la obra de David Held (Democracy and the Global Order) ocupa un lugar muy destacado, por no abordar las verdaderas causas del problema que nos ocupa, díficilmente van a proporcionarnos respuestas operativas y eficaces para resolver la crisis actual de la democracia representativa.

Todas estas propuestan olvidan, interesadamente o no, que la pérdida de espacios políticos en el seno del Estado no se ha producido por una incompatibilidad entre la realidad económica mundial y las realidades políticas geográficamente limitadas. Esto es, el problema no viene determinado por la mayor o menor extensión de una y otras. Si así lo fuera, la solución propuesta, ampliar el marco de la realidad política, tendría su sentido. Ocurre, sin embargo, que la incompatibilidad que subyace entre la mundialización económica y el Estado no es cuestión de límites espaciales, sino mucho más profunda. Se trata de la incompatibilidad existente entre la lógica del Estado que es la lógica de la política, esto es la de los valores, y la lógica de la vida económica, que es la del cálculo y de la ganancia (De Vega). Ampliar el ámbito de la organización política supondría por tanto, única y exclusivamente, en el mejor de los casos, trasladar ese conflicto al nuevo ámbito así surgido, pero en modo alguno implicaría su resolución.

El reto que la globalización y la crisis de la democracia nos plantea no es otro que el de la desmercantilización de la sociedad. Es preciso anteponer las necesidades de las personas a las exigencias de los 
mercados. Esta idea está implícita en nuestro Preámbulo, donde con toda claridad se subordina el progreso de la economía (un medio o instrumento) a la finalidad de asegurar a todos unna digna calidad de vida". En una sociedad democrática avanzada, los derechos en modo alguno pueden configurarse como mercancías (como ocurre en buena medida con la vivienda). Lo que el Preámbulo nos exige, en definitiva, y aquí reside su contradicción básica con la teoría y la práctica de la mundialización, es subordinar la economía a la política.

Mediante la afirmación de su voluntad de establecer "una sociedad democrática avanzada" el poder constituyente asigna, desde el mismo Preámbulo, como fines de los poderes públicos, la consecución de "un orden económico y social justo", y el aseguramiento a todos de «una digna calidad de vida». El imperio de la ley democrática, el progreso de la cultura y de la economía, son los medios o instrumentos con los que han de lograrse los anteriores objetivos.

Ahora bien, estos nobles y ambiciosos fines del Estado Social español han sufrido, en los últimos años, y en el contexto del proceso de integración europea, una notable conmoción, a la que resulta obligado hacer referencia en un balance sobre los veinticinco años del Preámbulo Constitucional.

El impacto producido sobre los fines del Estado, propugnados por el constituyente en el Texto preambular, por los Tratados comunitarios europeos es de tal intensidad y envergadura que voy a referirme solamente a una cuestión de extraordinaria gravedad.

El profesor Garcia Herrera, uno de los más cualificados estudiosos del Estado Social y de su crisis, ha puesto de manifiesto, con meridiana claridad e indiscutible acierto, cómo "los Tratados de la Unión Europea en sus dos últimas versiones de Maastricht y Amsterdam han avanzado en la determinación y concreción del soporte axiológico y finalístico de la construccción institucional» de Europa, y lo han hecho invirtiendo las coordenadas propias del Estado Social.

El artículo 9.2 de la Constitución española, de la misma forma que el artículo 3 de la Constitución italiana, explicita el fin fundamental del Estado Social español, forma histórica adoptada por el constituyente de 1978. Dicha disposición se configura como la más clara concreción de los enunciados preambulares. Si, como hemos expuesto, el constituyente de 1978 proclamó como objetivo primordial el establecimiento en España de una sociedad democrática avanzada, esto exige, inexcusablemente, el correspondiente deber de los poderes públicos de lograr la igualdad sustancial de los ciudadanos (art. 9. 2). 
Ahora bien, el Estado español al que el constituyente asignó como objetivos esenciales identificadores de su misma forma histórica, el establecimiento de una sociedad democrática avanzada, y el logro de la igualdad sustancial de todos los ciudadanos, se ha incorporado a un proceso de integración continental en virtud del cual ha asumido la obligación de subordinar los mencionados fines fundacionales a las exigencias del respeto a los principios de economía de mercado y de libre competencia (art. 4. 1 TUE) y al mantenimiento de la estabilidad de los precios (art. 4. 2 TUE). Dicha subordinación implica que los verdaderos fines del Estado son hoy estos últimos (estabilidad de precios, libre competencia..., etc.) y no los fijados por el constituyente. Innecesario resulta recordar que el poder constituyente derivado no ha tomado parte en esta trascendental operación y no lo ha hecho porque no se han activado los procedimientos de reforma constitucional qque hubieran encontrado en el Preámbulo uno de los más claros límites materiales implícitos a la misma, habida cuenta que este es un elemento axial de la fórmula política) sino que, una vez más, se ha recurrido a la modificación no formal del Texto fundamental, esto es a su mutación. Las consecuencias de todo ello, desde el punto de vista del principio democrático, son de indudable trascendencia.

Creo oportuno terminar esta breve exposición transcribiendo unas palabras del profesor García Herrera, que, en mi modesta opinión, contienen un muy acertado balance sobre la atenuada vigencia de nuestro Preámbulo constitucional. El Catedrático de la Universidad del País Vasco ha señalado en este sentido, cómo la gran novedad que se ha producido en estos años consiste en la transformación radical de las finalidades de nuestra Constitución: «Si en el Estado Social es admisible, dentro del marco constitucional como límite, la realización de políticas alternativas que modulen la forma de cumplimiento de los fines del art. 9. 2, la normativa europea cancela dicha posibilidad al establecer el marco único de funcionamiento $y$ establecer los fines de la Comunidad Europea en términos no coincidentes con los propios de la Constitución. En este sentido es nítida la contradicción entre la estrechez de posibilidades del primado exclusivo de la economía de mercado y de la libre competencia frente al abanico de opciones constitucionales que va desde la economía de mercado del art. $38 \mathrm{CE}$ a la reserva al sector público del art. 128. 2 CE y la programación democrática del art. $131 \mathrm{CE}$ ".

Tras esta exposición, necesariamente sintética y limitada al objeto de dar cuenta de una problemática (la relación entre el orden constitucional y el orden comunitario europeo) que, con toda seguridad, ocupará un lugar central en la reflexión constitucional de los próximos 
años, dedicaré los dos siguientes epígrafes a denunciar la existencia de dos asignaturas pendientes, esto es todavía no superadas veinticinco años después de aprobada la Constitución, y relacionadas más o menos directamente, con el tema que nos ocupa, el Preámbulo de la Constitución de 1978.

\section{PREÁMBULO CONSTITUCIONAL, SENTIMIENTO CONSTITUCIONALY ENSEÑANZA DE LA CONSTITUCIÓN}

En el transcurso de los debates que precedieron a la aprobación de la Constitución española de 1978, el escritor y economista José Luis Sampedro, en su calidad de senador de designación real, remitió al Presidente de las Cortes constituyentes, Antonio Hernández Gil, una carta en la que resaltaba la importancia de que la Constitución fuera aprobada precedida de un Preámbulo. La defensa de este texto introductorio se hacía en los siguientes términos: "Debería lograrse un texto lapidario capaz de motivar el juicio positivo de los ciudadanos conscientes a la hora del referéndum, porque es claro que no van a analizar toda la Constitución. Debería servir también como base de comentarios sencillos en las escuelas y en los medios de difusión. Debería servir, en fin, para demostrar que la Constitución no es sólo (y ya es mucho) un texto jurídico, sino también una palanca motivadora y estimulante para la democracia».

El Preámbulo de la Constitución de 1978, obra de los profesores Enrique Tierno Galván, Pablo Lucas Verdú, Raúl Morodo, Donato Fuejo y Enrique Linde, en cuanto sintetiza con precisión, brillantez y elegancia, el techo ideológico de la fórmula política de nuestra Constitución (Lucas Verdú) reúne las condiciones para poder desempeñar, con éxito, la noble y trascendental tarea que, con gran agudeza e indiscutible acierto, atribuía el senador Sampedro a los textos preambulares: servir de instrumento para la transmisión a las nuevas generaciones de españoles del sentimiento constitucional (Lucas Verdú).

Al conmemorar el vigésimoquinto aniversario de nuestra Constitución podemos y debemos preguntarnos en qué medida dicho sentimiento existe y se encuentra enraizado entre la población. Sin entrar a analizar este temá con la atención que requiere - dado que desborda el objeto de nuestro trabajo - si que podemos afirmar que es mucho lo que cabe hacer todavía en este campo. Y por lo que a nuestro tema atañe debemos denunciar el hecho de que las posibilidades pedagó- 
gicas y las potencialidades socializadoras del Texto preambular han sido por completo ignoradas $y$, por ello, desaprovechadas.

En este contexto, es preciso insistir, una vez más, en que la necesaria implantación en la sociedad española de un auténtico sentimiento constitucional exige como tarea inexcusable ubicar el conocimiento de la Constitución en las enseñanzas primaria y secundaria. Conocimiento que, por la índole específica de sus destinatarios y de los profesores que la imparten, no puede consistir, en modo alguno, en una explicación técnico-jurídica del régimen político, sino que lo que ha de intentarse es la transmisión del telos de la Constitución, de los principios ideológicos fundamentales que la informan. En esta línea, resulta obligado recordar y subrayar que, para la referida enseñanza, el texto preambular se configura como un instrumento de gran utilidad puesto que la comprensión de sus enunciados no ofrece grandes dificultades y en ellos se sintetiza el espíritu de la Constitución.

El objeto de la enseñanza que propugnamos, por tanto, ni puede ni debe centrarse en el texto articulado de la Constitución, lo cual es materia de la correspondiente asignatura de las Facultades de Derecho y Ciencias Políticas, sino en los elementos esenciales del constitucionalismo contemporáneo como fenómeno histórico, político, social, cultural e ideológico, esto es en las nociones de Estado de Derecho, convivencia democrática, progreso de la cultura, derechos y libertades, voluntad general, etc., conceptos y categorías todos ellos recogidos en el Preámbulo de la Constitución. Me atrevo a proponer como título de esta "asignatura pendiente" el siguiente: Hecho Constitucional.

Si en este vigesimoquinto aniversario; resulta tan obvio como lamentable, constatar que el Preámbulo no ha sido utilizado como instrumento para la enseñanza de los valores constitucionales, preciso es reconocer que no lo ha sido por la razón evidente de que la enseñanza de la Constitución no ha encontrado todavía su lugar en los planes de estudio de las enseñanzas medias.

Y esta ausencia u omisión, que no cabe calificar como olvido involuntario o inconsciente, puesto que voces muy autorizadas de insignes e ilustres constitucionalistas (Lucas Verdú, Torres del Moral) ya la habían advertido desde hace tiempo, resulta cada vez más preocupante.

En este año 2003 ha creado el Gobierno una Comisión Especial para organizar y coordinar una serie de actos conmemorativos de los veinticinco años de régimen constitucional. Pero todos estos actos $y$ 
otras iniciativas particulares (como la muy meritoria del profesorTorres del Moral de coordinar este número monográfico de la RDP), nos cueste más o menos reconocerlo, tendrán un alcance y eficacia muy puntuales, y aunque se plasmen en obras y volúmenes colectivos, sus destinatarios serán casi siempre, exclusivamente, miembros de la academia. Por ello creo que resulta obligado destacar que, si existe una auténtica voluntad política de conmemorar este importante aniversario, con algún tipo de medida efectiva, esto es cuyo significado alcance a una buena parte de la población, y de forma especial a las nuevas generaciones, dicha medida no puede ser otra que la inclusión del Hecho Constitucional en los planes de estudio de la enseñanza primaria y secundaria.

Lamentablemente, y pese a que tanto en el 2002 como en el 2003, se han Ilevado a cabo múltiples (y discutibles) reformas legislativas en el campo educativo, en todas ellas se ha pasado por alto tal cuestión. Y es en el contexto de estas reformas donde la omisión que nos ocupa reviste caracteres, francamente, alarmantes.

En un momento en que los máximos responsables educativos del país han decretado la obligatoriedad del estudio bien del hecho religioso considerado en abstracto, bien de una confesión religiosa concreta (obligatoriedad de dudoso encaje constitucional), la ausencia en los planes de estudio del fenómeno constitucional adquiere una dimensión verdaderamente preocupante. Y ello por la sencilla razón de que, dicho con el máximo de los respetos, es el Hecho Constitucional y no el Hecho Religioso, el que permite explicar y entender la vida humana en sociedad, y sus valores fundamentales (libertad e igualdad) esto es, la convivencia entre las personas en el marco de una comunidad nacional democrática. Convivencia que, salvo que pretendamos falsificar la realidad y la historia, debemos recordar que estuvo amenazada y no fue posible durante mucho tiempo precisamente a causa de la imposición del hecho religioso sobre la libertad de conciencia. Convivencia democrática y basada en el respeto a los derechos que todavía hoy no es posible, en muchos lugares del planeta, debido a que en ellas no se ha producido el fenómeno de secularización de la sociedad:

El estudio de esta asignatura "Hecho Constitucional" nos obligaría a reencontrar las raíces filósoficas del constitucionalismo, raíces que son las que, en definitiva, permiten explicar el significado, alcance y valor de lo que se ha dado en llamar civilización occidental. Aquellas raíces que con antecedentes en el pensamiento antiguo grecoromano, y meritorias aportaciones medievales como la de Marsilio de 
Padua, arrancan del Renacimiento con la oratio de Pico Della Mirandola (verdadero texto inaugural de la modernidad), encuentran sus primeras formulaciones en la obra de Maquiavelo y alcanzan su consolidación definitiva en la llustración.

El Preámbulo, insisto, es un buen instrumento para exponer las mencionadas raíces filosóficas del constitucionalismo, cuyo conocimiento considero indispensable para cualquier ciudadano. En el preámbulo están, de una u otra forma, con mayor o menor intensidad, Maquiavelo y Bodino, Montesquieu y Rousseau, Locke y Kant. Ante todo y sobre todo, el Preámbulo nos habla de una comunidad política (el pueblo español) que en uso de su soberanía ratifica una Constitución. Explicar esto a las nuevas generaciones de españoles nos obliga a recordar y subrayar que solamente cuando se impuso la convicción de que la comunidad política era una obra humana (y por tanto artificial y no divina y natural) fue posible que surgiera, desde esa afirmación inicial del principio democrático, el Estado Constitucional, como aquel Estado en el que el pueblo (soberano y titular indiscutible del poder constituyente) es el único sujeto legitimado para decidir el modo y la forma en que quiere ser gobernado (De Vega, Ruipérez). Estado Constitucional que si, para su nacimiento, tuvo que afirmar la autonomía de la política respecto de la religión (Maquiavelo), para su consolidación, tuvo que derrotar a los partidarios del principio monárquico, entre los que la Iglesia Católica figuró siempre como aliado incondicional.

En relación con esto último, debemos recordar que los redactores del Preámbulo excluyeron intencionadamente cualquier referencia religiosa. Porque lo cierto es que en los debates y discusiones que suelen preceder a la aprobación de los Preámbulos constitucionales, es habitual encontrar apasionadas polémicas sobre la conveniencia u oportunidad de incluir o no algún tipo de invocación a la divinidad o de referencia a la religión. El debate sobre el futuroTratado de la Unión Europea, entre partidarios y detractores de la apelación a la uherencia religiosa" o "cristiana" de Europa, nos proporciona el último y significativo ejemplo de lo que acabo de decir.

En cualquier caso, conviene destacar que, como el propio Enrique Tierno reconoce en sus memorias, varios miembros de la Comisión Constitucional advirtieron la falta de referencias a Dios y pretendieron subsanarla. $Y$ fueron circunstancias ajenas al debate parlamentario, las que determinaron que el Preámbulo, finalmente, se aprobara sin discusión, para no demorar la aprobación definitiva del Texto Constitucional. La brutal ofensiva terrorista de ETA, que en aque- 
llos días había perpetrado el más grave atentado desde el que le costara la vida al Almirante Carrero, como todo el mundo recordará, condujo a los diputados a cerrar los debates eludiendo la discusión sobre numerosos temas - como es el caso que nos ocupa- que en otro contexto hubieran provocado polémicas de altura.

"Cuando llegaron los demás miembros de la Comisión (...) - escribe Tierno en sus memorias - insinuaron también la necesidad de incluir la palabra Dios que nosotros no habiamos puesto. (...) En cuanto al nombre Dios, siempre me acuerdo de lo que me dijeron de niño y cuántas veces me reprendieron porque decía o empleaba esta palabra, porque la rigidez, casi calvinista, de quien me reprendía consideraba que la estaba pronunciando en vano. El principio 'no pronunciarás su nombre en vano' es una de las afirmaciones que están más vivas en mí espíritu desde la niñez y me parecía que la inclusión de la palabra Dios en la Constitución era pronunciar su nombre en vano. Creo que nadie iba a hacer caso de esta forma puramente superficial y convencional de hablar y que era mejor no aludir a la divinidad para no adquirir mayores compromisos de los que ya teníamos. No lo expliqué así, pero no hubo insistencia por parte de mis compañeros de Comisión, quizá por las circunstancias de perentoriedad a las que he aludido. En caso contrario imagino que hubiera habido larguísima discusiónn.

Como la hubo en torno a la posible inclusión en el Preámbulo de una referencia al inmediato pasado dictatorial. Cuestión, ésta, a la que voy a dedicar el último epígrafe de esta exposición.

\section{PREÁMBULO CONSTITUCIONAL, RECONCILIACIÓN NACIONALY MEMORIA HISTÓRICA}

Aunque existen diferentes tipos de Preámbulos constitucionales, en sentido estricto, el modelo más genuino es aquel que incluye dos tipos de enunciados: unos explicativos que, mirando al pasado, justifican la legitimidad del nuevo orden constitucional en contraposición a la realidad existente anteriormente; y otros que, con la vista puesta en el futuro, expresan los objetivos políticos fundamentales que el nuevo régimen pretende alcanzar (De Esteban y González-Trevijano).

Como es bien sabido, el Preámbulo de la Constitución de 1978 sólo contiene estos segundos y carece, por tanto, de cualquier enunciado explicativo o referencia a nuestro inmediato pasado. Ese olvido, en modo alguno involuntario como veremos, tuvo su sentido hace 
veinticinco años, y también su virtualidad, pero hoy veinticinco años después de aprobado el Texto fundamental nos obliga a replantearnos algunas cuestiones sobre las que me gustaría hacer la siguiente reflexión.

Al conmemorar el vigésimoquinto aniversario de nuestra Constitución creo que es preciso reconocer que entre las asignaturas pendientes para la definitiva consolidación de nuestra Democracia constitucional figura - junto a la inclusión de la enseñanza del Hecho Constitucional en los planes de estudio - la recuperación de la memoria histórica (V. Navarro). Lo de menos es ahora determinar si el pacto de silencio sobre nuestro pasado inmediato fue o no un precio que, ineludiblemente, hubo que pagar para que la transición democrática culminara con éxito. Probablemente así fue, pero hoy veinticinco años después, el levantamiento del velo del olvido se manifiesta como un deber moral inexcusable de quienes hoy disfrutamos de libertad respecto a los que durante décadas se vieron privados de ella. Este ejercicio colectivo de recuperación de la memoria de la II República y de la Dictadura de Franco es una empresa que a todos nos concierne, $y$ en mi modesta opinión, una buena forma de conmemorar el vigesimoquinto aniversario del texto constitucional. Como ha escrito Alfonso Guerra, uno de los grandes protagonistas y artífices del consenso constitucional, en su brillante, emotivo y sugerente prólogo a «El exilio español", es hora de reivindicar la libertad, «también la libertad para recordar, la memoria de los vencidos frente a la larga memoria de los vencedores".

En este contexto, me gustaría recordar al lector una fuerte discusión que tuvo lugar hace veinticinco años, junio de 1978, en el seno de la Comisión de Asuntos Constitucionales y Libertades Públicas del Congreso de los Diputados. Discusión que se produjo con objeto del debate sobre el Preámbulo Constitucional. Fueron sus protagonistas dos insignes Catedráticos de Derecho Político, los profesores Tierno Galván, Diputado del Partido Socialista Popular, y Fraga Iribarne, Diputado de Alianza Popular. No es irrelevante el hecho de que don EnriqueTierno, el "viejo profesor» hubiera sido privado de su cátedra universitaria por sostener ideas democráticas, y de que don Manuel Fraga hubiese formado parte de los Consejos de Ministros del dictador.

El profesor Tierno defendió en la citada Comisión una enmienda a favor de que la Constitución se abriera con una referencia histórica al pasado inmediato del siguiente tenor: «El pueblo español, después de un largo periodo sin régimen constitucional, de negación de las libertades públicas y de desconocimiento de los derechos de las 
nacionalidades y regiones que configuran la unidad de España, proclama, en uso de su soberanía(...). Por consiguiente, los representantes del pueblo español, ateniéndose al principio de reconciliación nacional, reunidos en Cortes, aprueban la siguiente Constitución". Merece la pena leer la transcripción completa de su intervención a favor de la citada enmienda. En aquella no por olvidada menos trascendente sesión, el "viejo profesor» afirmó: "Individualmente somos bastantes los españoles que teniendo buena memoria, hemos olvidado casi todo". Ahora bien, "la omisión total al largo periodo anterior dejaría insatisfecha a una gran parte de la opinión pública".

Don Manuel Fraga se opuso, rotundamente, a incluir en la Constitución referencia alguna al largo periodo de tiempo en el que los españoles estuvimos privados de libertad. Afirmó textualmente que había que "dejar en paz a la historia»: "porque si la Historia ha de ser el punto de partida de toda gran decisión que afecte al futuro, es muy difícil saber en qué momento de la Historia hay que empezar a echarse, digamos a nadar, porque algunos lo pondrían en el asesinato de Prim y otros, quizá en el destronamiento de Wamban. El entonces diputado por el PSOE, profesor Peces-Barba, en su relato sobre aquellas jornadas, se refiere a esta polémica como uuno de los pocos momentos de tensión personal" que se produjeron en las sesiones de la Comisión.

La intención de don Manuel Fraga era evidente, deseaba evitar la introducción del principio rupturista por muy atenuado que este se presentara en el texto constitucional. Para la derecha, el nuevo régimen se configuraba como una reforma del Estado franquista; para la izquierda, por el contrario, la Constitución de 1978 entroncaba con la legitimidad constitucional de la II República, interrumpida brutalmente por la guerra civil y el largo paréntesis dictatorial.

En su réplica, el profesor Tierno se reafirmó en lo dicho anteriormente, y pronunció unas palabras, cuyo eco, hoy, veinticinco años después, todavía resuena en los oídos de los demócratas: «Hay un gran sector del pueblo español que no se puede olvidar, el de los que han padecido, y lo menos que merecen es que se haga referencia a ese pasado, pues gracias a su padecimiento estamos venciendo ahoran.

Don Gregorio Peces-Barba en nombre del PSOE expresó su apoyó al "viejo profesor», pero la referida enmienda no prosperó. ¿Lo haría hoy, veinticinco años después? La resolución aprobada por la Comisión Constitucional del Congreso de los Diputados el pasado 20 de noviembre nos indica que, muy probablemente, sí. En dicha resolución, que contó con el voto afirmativo de los herederos políticos de 
don Manuel Fraga, se reafirma textualmente, «el deber de la sociedad democrática de proceder al reconocimiento moral de todos los hombres y mujeres que fueron víctimas de la guerra civil, así como de cuantos padecieron más tarde la represión de la dictadura franquista»; y se insta al Gobierno de la nación a «desarrollar una política integral de reconocimiento y de acción protectora económica y social de los exiliados de la guerra civil así como de los llamados "niños de la guerra"".

Lamentablemente, el viejo profesor no se encuentra entre nosotros para celebrar el vigésimoquinto aniversario de nuestro régimen democrático y esta victoria póstuma de la tesis que defendiera en los debates de la constituyente. Sirvan estas líneas de homenaje a su memoria y a la de cuantos, habiendo luchado por la recuperación de la libertad y por el restablecimiento de un régimen constitucional, han emprendido ya su último viaje. 